\title{
LOW OXYGEN TENSION IN THE MANAGEMENT OF NEWBORN INFANTS*
}

\author{
BY \\ SVEN SJÖSTEDT and GÖSTA ROOTH \\ From the Departments of Obstetrics and Gynaecology and of Internal Medicine, University Hospital, Lund, Sweden
}

(RECEIVED FOR PUBLICATION MAY 10, 1957)

Prolonged administration of oxygen in high concentrations to premature infants is now being abandoned in most countries, thanks to the studies on retrolental fibroplasia which have shown its harmful effects on the eyes. These studies have led to a revision of the indications for oxygen therapy and prompted renewed interest in its physiological bases in the neonatal period (Engle and Levine, 1955).

It is well known that the arterial oxygen tension is extremely low during intra-uterine life-a condition described by Barcroft as 'Mount Everest in Utero' (Eastman, 1954). Immediately after birth, the arterial oxygen tension increases to the same value as that of the adult, i.e., $100 \mathrm{~mm}$. $\mathrm{Hg}$ (Taylor, Govan and Scott, 1951). If the oxygen tension before birth is abnormally low as in asphyxiated infants (Eastman, 1936; Wilson, Torrey and Johnson, 1937; Rooth and Sjöstedt, 1955; Montgomery, Brandfass and First, 1956) or infants delivered by caesarean section (Eastman, 1936; Smith, 1939; Watts, Henderson, Kaump and Davis, 1951; Rooth and Sjöstedt, 1955), this increase will be more pronounced. These changes in the oxygen tension are known to produce important vasomotor reactions in the vessels of the brain, eyes and lungs, which in human infants are of special interest, due to the correlation between the two diseases retrolental fibroplasia and hyaline membrane and oxygen therapy. The frequent coexistence of retrolental fibroplasia and cerebral palsy as shown in the papers by Ingram and Kerr (1954) and Krause (1955) may perhaps also justify relating cerebral palsy to oxygen therapy.

It has been shown in man that an increase in oxygen tension causes a constriction and a decrease a dilatation of the retinal vessels (Cusik, Benson and Boothby, 1940), and these reactions have been studied in relation to retrolental fibroplasia (Huggert, 1952, 1953, 1954 and others). In the

\footnotetext{
* Based on a paper read before the VIIIth International Congress of Pediatrics in Copenhagen, July 24, 1956.
}

human brain the effect of changes in oxygen tension are the same (Tinel, 1927; Cobb and FremontSmith, 1931; Kety and Schmidt, 1948; Novack, Shenkin, Bortin, Goluboff, Soffe, Batson and Golden, 1953; Edstrom and Essex, 1956, and others). The vessels of the lungs seem to react in the opposite way to those of the brain and the retina (Ohlsson, 1947; Siebens, Smith and Storey, 1955; Hertz, 1956). Experimental and clinical studies also support the assumption that vascular reactions are of importance in the production of hyaline membrane disease (Tran Dinh De and Anderson, 1954; Bruns and Shields, 1954; Rogers and Gruenwald, 1956). If the infant is asphyxiated before birth the increase in oxygen tension after birth in room air may give an increased vascular response and produce manifestations of disease. Moreover the premature infant is abruptly prevented from spending another one or two months in the uterus at a very low oxygen tension. Its enzyme system is immature and its vessels are less resistant to the strain of the vasomotor reactions caused by the sudden increase in the oxygen tension. This is shown by the very strong correlation between prematurity and retrolental fibroplasia and hyaline membrane disease.

On the basis of these considerations it seems logical to keep premature and asphyxiated infants in an atmosphere of lower oxygen content for some time, perhaps for a period corresponding to full term (Rooth and Sjöstedt, 1954 (cited by Rooth and Sjöstedt, 1956)). Then their first weeks after birth will bear some resemblance to their interrupted intra-uterine life.

Knowing how well newborn infants tolerate extreme hypoxia, we considered that an oxygen tension of $115 \mathrm{~mm}$. of mercury in the ambient air should not involve undue risks. This tension has already been employed in respiratory studies in infants, but only for a short time (Cross and Oppé, 1953; Jonxis, 1953; Miller and Smull, 1955). 
Before starting the treatment of infants with low oxygen tension, we studied its effect on animals. For a period of time varying from one to 40 days, more than 200 newborn rats were continuously kept in airtight cages with a mixture of $15 \%$ oxygen and $85 \%$ nitrogen. There was no increased mortality among these young rats and the results were so encouraging that we felt justified in beginning to extend the treatment of infants over long periods. Some results of the animal experiments are published (Rooth and Sjöstedt, 1957).

\section{Technique}

The infants were kept in ordinary incubators. The desired oxygen concentration was obtained by blowing a mixture of $15 \%$ oxygen and $85 \%$ nitrogen at a rate of 5 litres/min. through the incubator. The oxygen tension within the incubator was controlled regularly with a Beckman D oxygen analyser.

During the first months of the study, the temperature in the incubator was $25^{\circ}$ to $27^{\circ} \mathrm{C}$. but was later reduced to $23^{\circ}$ to $25^{\circ} \mathrm{C}$. The relative humidity was maintained at about $75 \%$. The infants were brought out into room air for feeding and nursing, but otherwise they were kept continuously in the atmosphere of $15 \%$ oxygen. Recently we have started to feed the infants by a continuous milk drip via an indwelling naso-gastric tube. The infants are now in the incubators at least 23 hours a day.

\section{Material}

At present 33 infants have been treated; 21 of these were delivered at full term, and 12 were premature. The premature infants weighed between 520 and 2,200 g. at birth, and some were asphyxiated at birth.

The infants treated can be divided into three groups:

(1) Fifteen healthy full-term infants treated with $15 \%$ oxygen for one to three hours. These infants were the first we treated in order to acquire experience and to measure their arterial oxygen saturation during the treatment. The infants were from 1 to 5 days old when placed in the incubator.

(2) Six other full-term infants, healthy or asphyxiated, were treated for a period up to seven days. The infants were placed in the incubator immediately after birth or after resuscitation.

(3) Twelve premature infants were treated for a period up to five weeks. These infants were also placed in the incubator immediately after birth or after resuscitation.

On two occasions the smaller one of two premature twins was placed in the incubator whereas the other twin was treated in room air and at room temperature.

During the infants' stay in the incubator, analyses were made of the blood and urine, and the heart rate and respiration rate were registered. The vessels of the retina were inspected by ophthalmoscopy. The results of these studies will be reported later in detail. In this preliminary paper we will only draw attention to a few points.

\section{Results}

When a full-term infant aged 1 to 5 days is placed in an incubator containing $15 \%$ oxygen, it may be a little dyspnoeic and a little cyanotic during the first few minutes. After that it reassumes a normal appearance and usually falls asleep. The infant's arterial oxygen saturation was measured with a Millikan oxymeter, the earpiece of which had been slightly altered in order to fit the ear of the child. The oxymeter was preset at $95 \%$ saturation when the infant was breathing air. When exposed to $15 \%$ oxygen the arterial oxygen saturation of the infant falls by about $10 \%$. In all cases the value lies between 80 and $90 \%$ and remains at the same level. Only when the children start crying does the oxygen saturation increase a little. The results of these analyses were most uniform and a typical finding is given in Fig. 1.

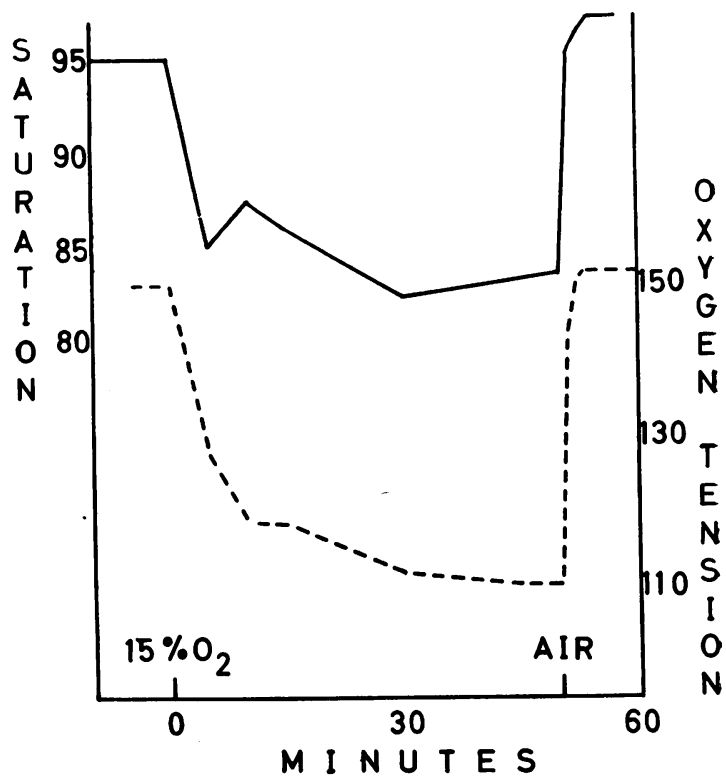

Fig. 1.-Arterial oxygen saturation and oxygen tension in incubator during treatment with $15 \%$ oxygen. Arterial oxygen saturation in per cent. Oxygen tension in incubator in $\mathrm{mm}$. of mercury.

A newborn full-term infant exposed to $15 \%$ oxygen does not become cyanotic and has no respiratory difficulties. If it is cyanotic when put into the incubator, cyanosis soon disappears and the infant assumes a healthy pink colour. Breathing is deep and quiet and dyspnoea does not occur. In some respects these children, when treated for a few days in $15 \%$ oxygen, behave like normal but older children. They are in excellent condition with fairly deep breathing and distinct bradycardia. 
Their pulse rate is 100 to 110 , their temperature is a little lower than normal, and no side-effects are observed.

In the main premature infants behave like the full-term infants. They are often a little cyanotic and, like other premature infants, during the first few days they have attacks of cyanosis and dyspnoea, but not more often than is usual. In fact, if anything cyanosis and dyspnoea occur more rarely. Their temperature lies between $33^{\circ} \mathrm{C}$. and $36^{\circ} \mathrm{C}$. for one or two weeks and after that it is normal. These premature infants are also in excellent condition and no side-effects have been observed. Two examples are given in Figs. 2 and 3.

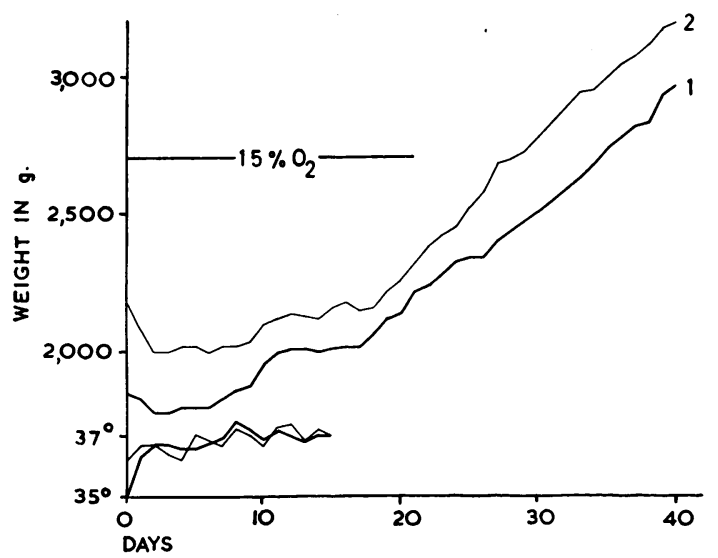

Fig. 2.-Healthy 29-year-old 5-para. Last menstrual period December 16. On August 2 the membranes ruptured and four days later delivery of dichorial twins. Girl 1 spontaneous delivery in o.a. presentation. Weight $1,850 \mathrm{~g}$., length $43 \mathrm{~cm}$. Girl 2 born after version and extraction. Weight 2,180 g., length $49 \mathrm{~cm}$. Girl 1 in incubator, girl 2 in room air. During treatment girl 1 in better condition than her sister. Re-examination after three and six months showed normal development and normal retinal vessels in both infants.

Three of the infants treated have died. Their case histories are given below.

\section{Case Histories}

Case 1. Healthy 26-year-old primipara. Normal delivery of $520 \mathrm{~g}$. infant at 22 weeks who lived 19 hours in the incubator with $15 \%$ oxygen. At necropsy, the lungs were well aerated and nothing pathological could be seen.

Case 2. Twenty-three-year-old primipara with diabetes and nephropathy since childhood developed gross oedema, proteinuria and raised blood pressure and diabetic retinopathy during pregnancy. Infant born by caesarean section at 28th week and lived six hours in poor condition. At necropsy, intraperitoneal haemorrhage from the umbilical vessels.
Case 3. Thirty-nine-year-old primipara developed antepartum bleeding from first degree placenta praevia at sixth month and bled continuously until delivery at 34 weeks. The infant weighed $2,080 \mathrm{~g}$. and had signs of intracranial haemorrhage with feeble cry and intermittent attacks of cyanosis. It died after nine hours. At necropsy, intracerebral and intraventricular haemorrhage.

These case histories show that the prognosis of these three infants was already grave at birth and that the outcome was not affected by the treatment We do not feel that the fatal outcome in these cases invalidates the favourable experience in the other cases.

Our material is too limited to tell whether there is

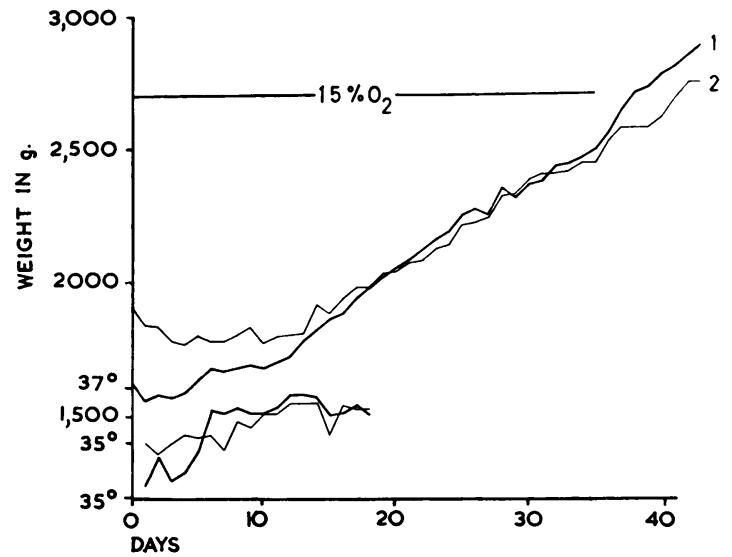

Fig. 3.-Healthy 27-year-old primipara. Last menstrual period May 20. The membranes ruptured January 6 and delivery of dichorial twins next day. Girl 1 spontaneous delivery in o.a. presentation. Weight $1,620 \mathrm{~g}$., length $40 \mathrm{~cm}$. Girl 2 born after version and extraction. Weight $1,900 \mathrm{~g}$., length $41 \mathrm{~cm}$. Girl 1 in incubator, girl 2 in room air. Girl 1 in better condition during treatment than her sister and doubled her weight in seven weeks. Re-examination after three months showed normal development and normal retinal vessels in both infants.

a greater survival rate with this treatment or fewer cases of retrolental fibroplasia. hyaline membrane disease or cerebral palsy. However, the most striking advantage so far has been the favourable general condition of these infants during the treatment. In the two sets of twins which we have observed (Figs. 2 and 3 ) each twin kept in $15 \%$ oxygen was in a markedly better condition than their sisters kept in room air. The treated infants seem to become more advanced and behave like normal older children. Our experience encourages us to continue treating asphyxiated and premature infants with $15 \%$ oxygen.

\section{Summary}

Twenty-one full-term infants and 12 premature infants were treated in low oxygen tension-15\% 
oxygen and $85 \%$ nitrogen-up to five weeks continuously. There seems to be no risk in the treatment and the treated infants are in an excellent condition.

\section{REFERENCES}

Bruns, P. D. and Shields, L. V. (1954). Amer. J. Obstet Gynec., 67, 1224.

Cobb, S. and Fremont-Smith, F. (1931). Arch. Neurol. Psychiat. (Chicago), 26, 731 .

Cross, K. W. and Oppé, T. E. (1953). In Anoxia of the New-born Infant, A Symposium Organized by the Council for International Organizations of Medical Sciences, pp. 143-156. Oxford.

Cusick, P. L., Benson, O. O. and Boothby, W. M. (1940). Proc. Mayo Clin., 15, 500

Eastman, N. J. (1936). Amer. J. Obstet. Gynec., 31, 563. (1954). Ibid., 67, 701.

Edstrom R. F. S and Essex, H. E (1956), Neurology, 6, 118.

Engle, M. A. and Levine, S. Z. (1955). A.M.A. J. Dis. Child. 89, 316

Hertz, C. W. (1956). Klin. Wschr., 34, 472.

Huggert, A. H. (1952). Acta paediat. (Uppsala), 41, 463. (1953). Ibid. 42, 147.

Ingram, T. T. S. and Kerr, J. D. (1954). Archives of Disease in Childhood, 29, 282.
Jonxis, J. (1953). In Anoxia of the New-born Infant, A Symposium Organized by the Council for International Organizations of Medical Sciences, pp. 127-134. Oxford.

Kety, S. S. and Schmidt, C. F. (1948). J. clin. Invest., 27, 484

Krause, A. C. (1955). A.M.A. Arch. Ophthal., 53, 522.

Miller, H. C. and Smull, N. W. (1955), Pediatrics, 16, 93.

Montgomery, T. L Brandfass, R. T and First, H. E. (1956). Amer. J. Obstet. Gynec., 71, 1 .

Novack, P., Shenkin, H. A., Bortin, L., Goluboff, B., Soffe, A. M., Batson, P. and Golden, D. (1953). J. clin. Invest., 32, 696.

Ohlsson, W. T. L. (1947). Acta med.scand., Suppl. 190.

Rogers, W. S. and Gruenwald, P. (1956). Amer. J. Obstet. Gynec., $71,9$.

Rooth, G. and Sjöstedt, S. (1954). Cited by Rooth and Sjöstedt (1956).

- - (1955). Acta obstet. gynec. scand., 34, 442.

- (1956). Nord. Med., 56, 992.

- (1957). Scand. J. clin. Lab. Invest., 9, 174

Siebens, A. A., Smith, R. E. and Storey, C. F. (1955). Amer. J. Physiol., 180, 428.

Taylor, E. S., Govan, C. D. and Scott, W. C. (1951). Amer. J. Obstet. Gynec., 61, 840.

Tinel, J. (1927). C.R. Soc. Biol. (Paris), 96, 665

Tran Dinh De and Anderson, G. W. (1954). Amer. J. Obstet. Gynec., 68, 1557.

Watts, J., Henderson, H., Kaump, D. H. and Davis, R. M. (1951) Ibid., 61, 1025 .

Wilson, R. A., Torrey, M. A. and Johnson, K. S. (1937). Surg. Gynec. Obstet., 65, 601 . 